\title{
Formulation and evaluation of liquisolid compact of azithromycin dihydrate
}

\author{
Sayani BHATTACHARYYA $1,2 *(\mathbb{D})$, Imran PASHA 1 (D), Anisha VERMA 1 (D), Ridhi KOTHAPALLI 1 (D), \\ Fajas JAFAR ${ }^{1}$ (D), Kavya HR ${ }^{1}$ (D)
}

1 Department of Pharmaceutics, Krupanidhi college of Pharmacy, 12/1, Chikka Bellandur, Carmelaram Gunjur Road Varthur Hobli, Off Sarjapur Rd, Bengaluru, Karnataka 560035, India.

2 Department of Pharmaceutics, Faculty of Pharmaceutics, Krupanidhi college of Pharmacy, 12/1, Chikka Bellandur, Carmelaram Gunjur Road Varthur Hobli, Off Sarjapur Rd, Bengaluru, Karnataka 560035, India.

* Corresponding author Email: sayanibh@gmail.com (S.B.); Tel No : +91-984-556 1865.

Received: 03 April 2019 / Revised: 10 July 2019 / Accepted: 31 July 2019

\begin{abstract}
Azithromycin dihydrate is a macrolide antibiotic and belongs to BCS class II drugs. The present study aims at the preparation of liquisolid compact of azithromycin dihydrate with an aim to improve the solubility of the drug. The liquid solid system uses a nonvolatile solvent to dissolve the drug. The solution or suspension of drug is converted into a free flowing dry and compressible powder in an admixture of coating and carrier material calculated mathematically. In this study Avicel PH102 and Aerosil 200 were used as carrier and coating material respectively. Propylene glycol was used as the nonvolatile solvent. Using different excipient ratio six formulations were made and evaluated for flowability and compressibility characteristics. Drug excipient interaction study was performed through Fourier transform infrared spectroscopy (FTIR). The formulations were subjected to statistical analysis. Optimization of the formulation was done through JMP V8.0 software. The optimized formulations were evaluated for flowability, compressibility study, thermal analysis by differential scanning calorimetry (DSC) and comparative dissolution study with pure drug. The optimized formulations showed a good flow property and compression characteristics. The FTIR study revealed no physical interaction of the drug with the excipient. The DSC thermograms proved the conversion of crystalline structure of the drug into its amorphous form. The comparative dissolution study of the optimized formulations with the pure drug revealed significant improvement of solubility of azithromycin dihydrate in liquid solid compact. Therefore, it can be concluded that a free flowing, non-adherent, dry and compressible powder of azithromycin dihydrate can be prepared using liquid solid compact technology.
\end{abstract}

KEYWORDS: Azithromycin dihydrate; liquisolid compact; solubility; optimization; DSC.

\section{INTRODUCTION}

Oral bioavailability is a concern of many drugs due to their poorly solubility. The solubility and dissolution are the primary challenges for the formulation scientist. Various methods like cosolvency, micronization, nanonization, self-emulsification, solubilization, solid dispersion and complexation are employed in the enhancement of solubility of poorly soluble drugs. Another promising technique to improve solubility of poorly soluble drug is liquisolid system [1, 2]. A liquisolid system refers to formulation formed by conversion of powder drug into drug suspension or drug solution in a non-volatile solvent and then conversion into compressible pulverized mixture in a blend of carrier and coating material $[3,4]$. The nonvolatile solvents generally used are propylene glycol, glycerin, polysorbates, fixed oils and polyethylene glycols etc. The solubilization or molecular dispersion of drug in the nonvolatile solvent increases the surface area and wetting properties. The use of carriers and coating material in suitable proportion renders the powder mixture dry, non-adherent, free- flowing and compressible [5]. The carriers are porous materials, with high surface area and liquid absorption capacity. Carriers used are starch, microcrystalline cellulose, lactose, which help in the absorption of the nonvolatile solvent. The fine particle size of coating materials forms a uniform film around the carrier to prevent aggregation. This helps in reduction of interparticle friction and promotes flowability. The coating materials used are aerosil, cab-o-sil etc. The drug gets molecularly distributed in the liquisolid compact and thereby enhance dissolution and improves oral bioavailability. Azithromycin dihydrate (AZ) belongs to the class macrolide antibiotics. According to bio pharmaceutical classification

How to cite this article: Bhattacharya S, Pasha I, Verma A, Kothapalli R, Jafar F, Hr K. Formulation and evaluation of liquisolid compact of azithromycin dihydrate. J Res Pharm. 2019; 23(6): 1022-1032. 
system it belongs to class II drug. The poor solubility of azithromycin dihydrate limits the rate of dissolution and hence bioavailability [6, 7]. Therefore, liquisolid compact of azithromycin dihydrate can be a novel technology for improving solubility of the drug using suitable carrier and coating material. Propylene glycol was selected as the nonvolatile liquid. Avicel PH102 and Aerosil 200 were selected as the carrier and coating material respectively. This study emphasizes on the preparation and characterization of liquid solid compacts of azithromycin dihydrate using powder solution technology.

\section{RESULTS AND DISCUSSION}

\subsection{Solubility studies}

Solubility studies were performed to select the best nonvolatile solvent for liquisolid system of azithromycin dihydrate. Table 1 explains the results of solubility studies. Azithromycin dihydrate showed maximum solubility in propylene glycol, hence the same was selected as non-volatile solvent for preparing the compacts.

Table 1. Solubility of azithromycin dihydrate in different solvents.

\begin{tabular}{cc}
\hline Solvents & Solubility $(\mathrm{mg} / \mathrm{ml})$ \\
\hline Distilled water & $0.0024 \pm 0.05$ \\
PEG 400 & $0.1142 \pm 0.12$ \\
Tween 20 & $0.1857 \pm 0.08$ \\
Propylene glycol & $0.5857 \pm 0.11$ \\
\hline
\end{tabular}

*All the values are mean of triplicates \pm SD.

\subsection{FTIR Studies}

Pure azithromycin dihydrate showed the characteristic peaks for $\mathrm{C}-\mathrm{H}$ stretching at $2971.30 \mathrm{~cm}^{-1}, \mathrm{C}=\mathrm{O}$ ketone $1718.56 \mathrm{~cm}^{-1}$, and C-O-C ether stretching at $1186.97 \mathrm{~cm}^{-1}$. The FTIR spectra of the physical mixtures of drug, carriers, coating and solvent had expressed all the characteristic peaks of azithromycin dihydrate confirming that all the functional groups were well preserved as shown in Figure 1. There was no appearance or disappearance of any characteristics peak which indicated the absence of any chemical interaction between the drug and the excipient. Therefore, it can be concluded that they are compatible to each other.

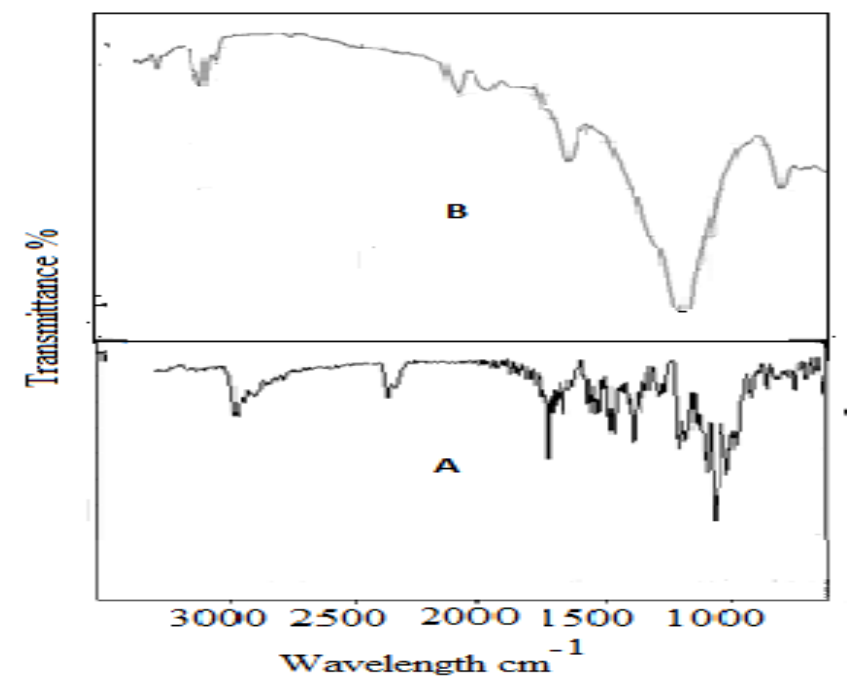

Figure 1. FTIR of A. Pure drug. B. Physical mixture of drug and excipient.

\subsection{Liquid retention potential of carrier and coating material}

The angle of slide was found to be $32^{\circ}$. The $\varphi$ values of the carrier (Avicel PH102) and coating material (Aerosil) in propylene glycol were found to be 0.125 and 0.275 respectively [8]. 


\subsection{Mathematical model for designing liquisolid compacts}

The mathematical equation (Eq. 1) for calculation of loading factor was modified as follows.

$$
L f=0.125+0.275\left(\frac{1}{R}\right)
$$

\subsection{Employment of experimental design and evaluation of runs}

Employing the design six batches of liquisolid compact formulations were made. All the formulations were subjected for pre-compression flow property studies, drug content and dissolution. The effects of carrier and coating material on the flow property, drug content and dissolution are presented in table 2 .

Table 2. Evaluation of liquisolid compacts.

\begin{tabular}{cccccc}
\hline Formulation code & $\begin{array}{c}\text { Angle of } \\
\text { repose }\end{array}$ & Carr's index & Hausner's ratio & $\begin{array}{c}\text { Drug } \\
\text { Content }\end{array}$ & $\begin{array}{c}\text { \%CDR at 45 } \\
\text { mins }\end{array}$ \\
\hline F1 & $31 \pm 0.5$ & $9.34 \pm 0.001$ & $1.31 \pm 0.001$ & $95 \pm 0.04$ & $75 \pm 0.23$ \\
F2 & $34 \pm 0.5$ & $7.47 \pm 0.003$ & $1.28 \pm 0.001$ & $93 \pm 0.01$ & $74 \pm 0.52$ \\
F3 & $26 \pm 0.3$ & $4.00 \pm 0.008$ & $1.03 \pm 0.002$ & $96 \pm 0.03$ & $89 \pm 0.26$ \\
F4 & $28 \pm 0.4$ & $4.45 \pm 0.005$ & $1.08 \pm 0.003$ & $97 \pm 0.06$ & $88 \pm 0.61$ \\
F5 & $25 \pm 0.5$ & $3.15 \pm 0.004$ & $1.04 \pm 0.002$ & $98 \pm 0.03$ & $91 \pm 0.22$ \\
F6 & $28 \pm 0.4$ & $4.50 \pm 0.003$ & $1.02 \pm 0.003$ & $96 \pm 0.06$ & $85 \pm 0.34$ \\
\hline
\end{tabular}

*All the values are mean of triplicates \pm SD.

Analysis of variance (ANOVA) was applied for testing the significance of the predicted model. P value less than 0.05 indicated (as shown in table 3 ) that the assumed regression model was significant and valid for the examined responses. The R square value (greater than 0.8 ) also proved the significance of the model with respect to the responses as shown in table 3 and Figure 2.

Table 3. ANOVA summary output for regression model.

\begin{tabular}{|c|c|c|c|c|c|}
\hline Source & DF & Sum of Squares & Mean Square & F Ratio & R Square \\
\hline \multicolumn{6}{|c|}{ ANOVA results for $\% C D R$} \\
\hline Model & 2 & 235.553 & 117.77 & 9.8752 & 0.87 \\
\hline Error & 3 & 35.77 & 11.927 & Prob $>$ F & \\
\hline C. Total & 5 & 271.33 & & 0.0479 & \\
\hline \multicolumn{6}{|c|}{ ANOVA results for Angle of repose } \\
\hline Model & 2 & 50.894034 & 25.4470 & 17.1966 & 0.92 \\
\hline Error & 3 & 4.439300 & 1.4798 & Prob $>$ F & \\
\hline C. Total & 5 & 55.333333 & & 0.0227 & \\
\hline \multicolumn{6}{|c|}{ ANOVA results for Carr's Index } \\
\hline Model & 2 & 26.576935 & 13.2885 & 20.9215 & 0.93 \\
\hline Error & 3 & 1.905477 & 0.6352 & Prob $>$ F & \\
\hline C. Total & 5 & 28.482412 & & 0.0173 & \\
\hline \multicolumn{6}{|c|}{ ANOVA results for Hausner's ratio } \\
\hline Model & 2 & 0.08681816 & 0.043409 & 29.6757 & 0.95 \\
\hline Error & 3 & 0.00438835 & 0.001463 & Prob $>$ F & \\
\hline C. Total & 5 & 0.09120651 & & 0.0106 & \\
\hline
\end{tabular}

Results of ANOVA for the dependent variables with respect to the independent variables are listed in Table 4. ANOVA at significance level $\mathrm{P}<0.05$ revealed that coating material had significant effect on drug dissolution and flow properties. The contour plot for the responses is shown in Figure 3. 


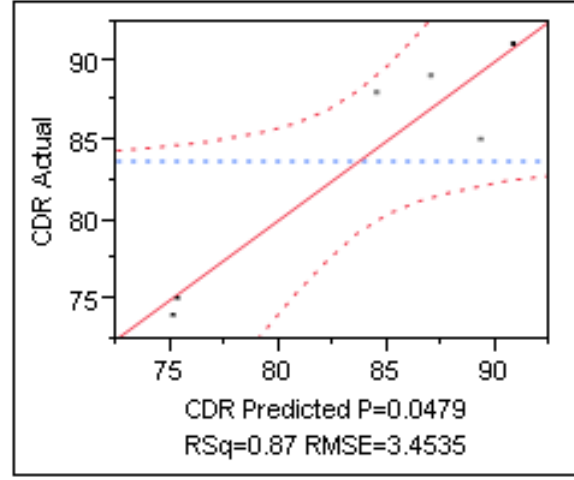

A

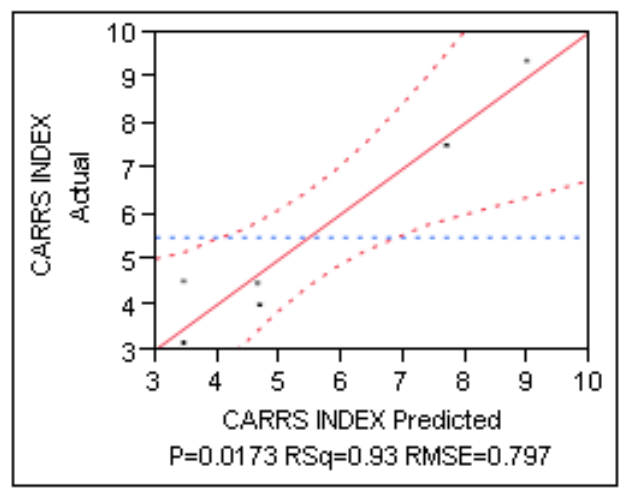

C

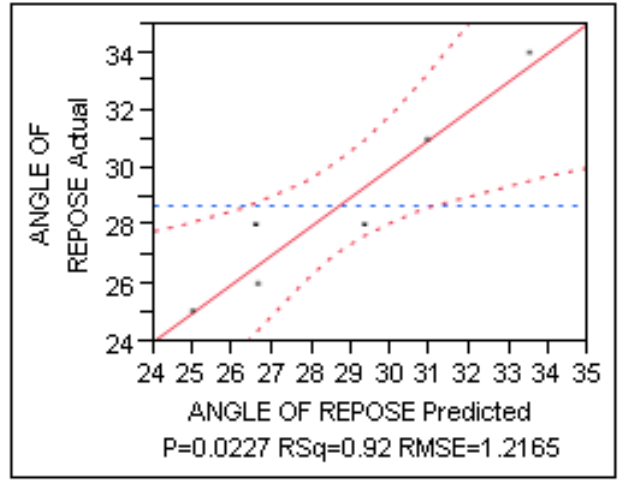

B

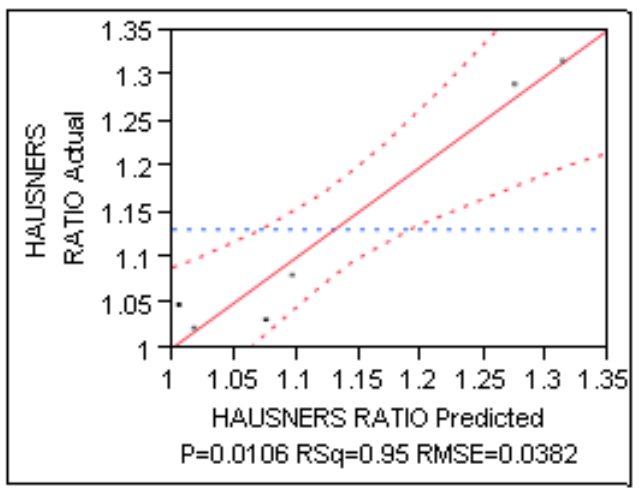

D

Figure 2. Actual vs. predicted plot A: CDR, B: Angle of repose, C: Carr's Index, D. Hausner's ratio.

Based on the target product quality, the optimized design from multidimensional combinations of coating and carrier ratio was achieved statistically using JMP V8 software. Each response was associated with the desirability function. The optimum was the point with the highest value for desirability. The prediction profiler showed (Figure 4) desirability of 0.90 at an excipient ratio of 21.67 with a loading factor 0.137 and hence was selected as optimized formulation.

Table 4. Parameter estimates summary.

\begin{tabular}{|c|c|c|c|c|}
\hline Term & Estimate & Std Error & t Ratio & Prob $>|t|$ \\
\hline \multicolumn{5}{|c|}{ Parameter estimates for $\% C D R$} \\
\hline Intercept & 81.806712 & 1.502753 & 54.44 & $<.0001^{*}$ \\
\hline COATING & -8.449319 & 1.9021 & -4.44 & $0.0212^{*}$ \\
\hline CARRIER & -1.983658 & 1.993092 & -1.00 & 0.3930 \\
\hline \multicolumn{5}{|c|}{ Parameter estimates for Angle of repose } \\
\hline Intercept & 29.29144 & 0.529331 & 55.34 & $<.0001^{*}$ \\
\hline COATING & 3.7715953 & 0.669997 & 5.63 & $0.0111^{*}$ \\
\hline CARRIER & 2.1182879 & 0.702048 & 3.02 & 0.0569 \\
\hline \multicolumn{5}{|c|}{ Parameter estimates for Carr's Index } \\
\hline Intercept & 6.2018242 & 0.346794 & 17.88 & $0.0004^{*}$ \\
\hline COATING & 2.738886 & 0.438953 & 6.24 & $0.0083^{*}$ \\
\hline CARRIER & -0.031857 & 0.459951 & -0.07 & 0.9491 \\
\hline \multicolumn{5}{|c|}{ Parameter estimates for Hausner's ratio } \\
\hline Intercept & 1.1690209 & 0.016643 & 70.24 & $<.0001^{*}$ \\
\hline COATING & 0.1602077 & 0.021065 & 7.61 & $0.0047^{*}$ \\
\hline CARRIER & 0.0162935 & 0.022073 & 0.74 & 0.5139 \\
\hline
\end{tabular}

*indicates significance. 


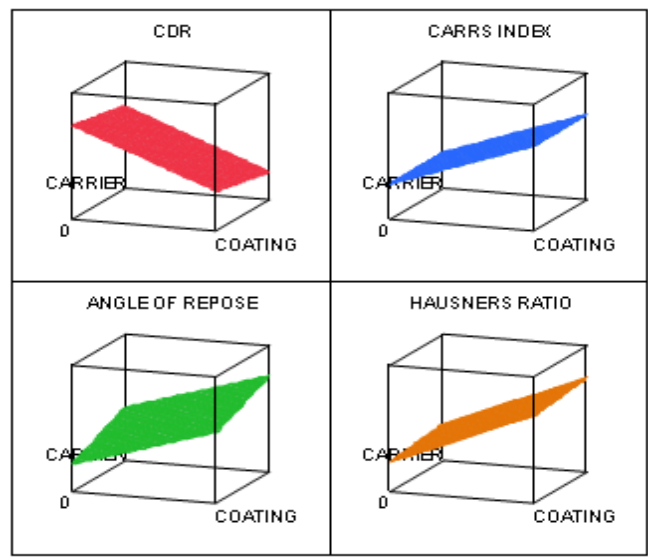

Figure 3. Contour plots of the responses.

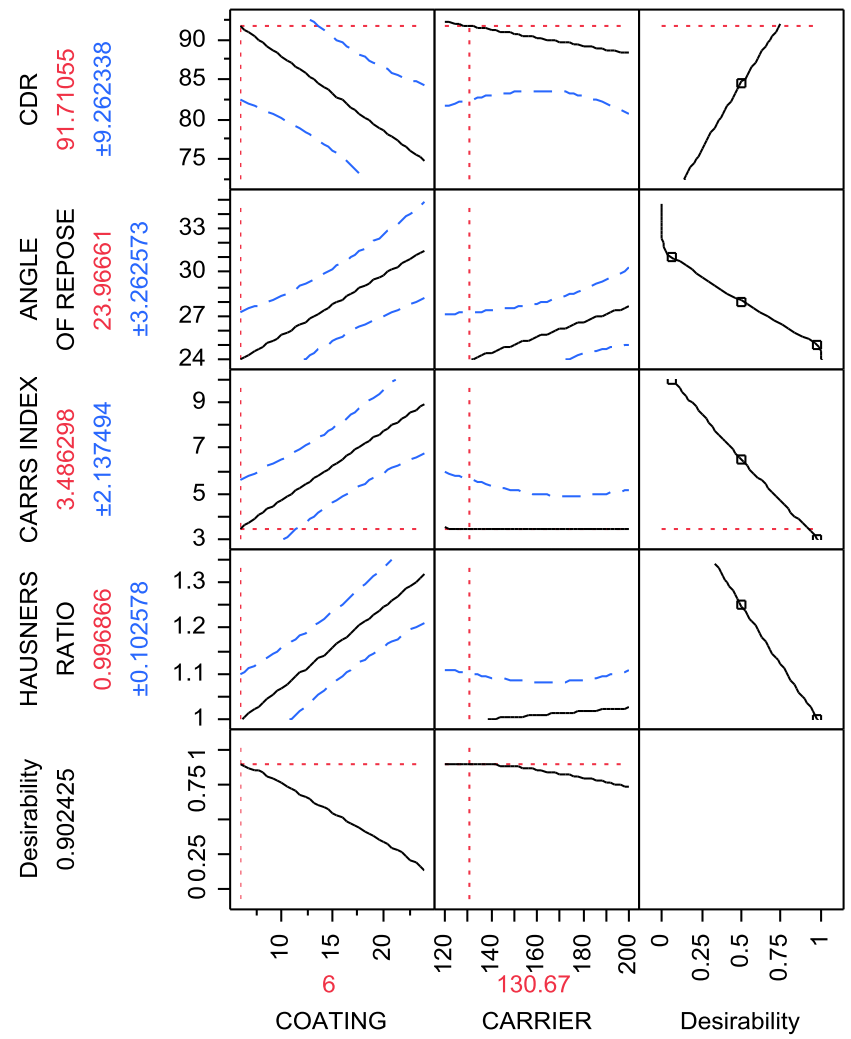

Figure 4. Prediction profiler.

\subsection{Optimized formulation}

Three optimized formulations of liquid solid compacts of azithromycin dihydrate were prepared at an excipient ratio of 21.67. The composition of the optimized formulation is shown in table 5 .

Table 5. Composition of optimized formulations.

\begin{tabular}{lc}
\hline Ingredients & F opt \\
\hline Azithromycin dihydrate in propylene glycol $(\% \mathrm{w} / \mathrm{w})$ & 25 \\
Excipient Ratio $(\mathrm{R})$ & 21.67 \\
Loading Factor $(\mathrm{Lf})$ & 0.137 \\
Magnesium stearate $(\% \mathrm{w} / \mathrm{w})$ & 5 \\
\hline
\end{tabular}


Evaluation of responses of the optimized formulations showed $90.36 \%$ release of drug in 45 minutes, with good flow property (angle of repose $-25^{\circ}$ ) and compressibility (Carr's index 3.9, Hausner's Ratio-0.95) The predicted and experimental values of all the response variables like cumulative drug release, angle of repose, Carr's index and Hausner's ratio were shown in table 6. The \% bias was calculated and found that bias was less than $5 \%$ for each response at significance level $\mathrm{P}<0.05$. This indicates statistical equivalence between experimental and predicted values, demonstrating the validity of the selected formulation variables.

Table 6. Validation table.

\begin{tabular}{lccc}
\hline Solution of responses & Predicted mean & Observed Mean* & Bias (\%) \\
\hline CDR at 45 mins & $91.71 \pm 9.26$ & $90.36 \pm 2.34$ & 1.47 \\
Angle of repose & $23.96 \pm 2.26$ & $25 \pm 1.12$ & -4.34 \\
Carr's Index & $3.47 \pm 2.13$ & $3.97 \pm 1.11$ & -14.4 \\
Hausner's Ratio & $0.996 \pm .10$ & $0.95 \pm 0.05$ & 4.60 \\
\hline
\end{tabular}

* All the values are mean of triplicates \pm SD.

$\%$ Bias $=(($ Predicted mean - Observed mean $) /$ Predicted mean $) * 100$.

\subsection{Comparative dissolution study}

The optimized formula equivalent to $250 \mathrm{mg}$ drug was taken for comparative dissolution study with pure drug. The release study revealed that the experimental product showed significant improvement in dissolution. The dissolution profile is shown in Figure 5.

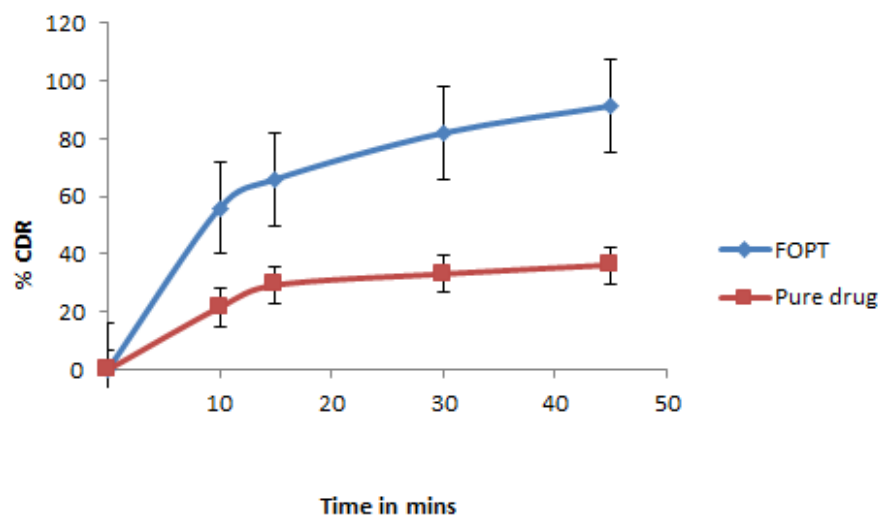

Figure 5. Comparative dissolution of F opt with pure drug $(n=3)$.

\subsection{DSC study}

The thermogram of pure azithromycin dihydrate showed an endothermic peak at $115.77^{\circ} \mathrm{C}$ corresponding to its melting point, indicating the crystalline nature of the drug. DSC thermogram of optimized liquisolid system showed a broad peak at around $90^{\circ} \mathrm{C}$, which revealed the conversion of crystalline form to amorphous form as shown in Figure 6. It can be concluded that the drug is converted into its amorphous form and this conversion leads to the improvement in solubility of the drug.

\section{CONCLUSION}

Azithromycin dihydrate was found to be more soluble in propylene glycol and was selected as the nonsolvent for the compacts. Avicel PH 102 and Aerosil 200 were selected as carrier and coating material. The liquisolid compact of azithromycin dihydrate showed significant improved in flowability and compression qualities in terms of angle of repose, Carr's index and Hausner's ratio. The compacts were found to be nonadherent, dry and free flowing. The optimized system on further studies showed the good flow properties and high drug release in 45 mins. The release was compared with pure drug, showed a marked increase in solubility. Therefore, it can be concluded that with the help of mathematical model and the statistical design liquid solid compact of azithromycin dihydrate with acceptable in vitro release and compression qualities can be prepared successfully. 


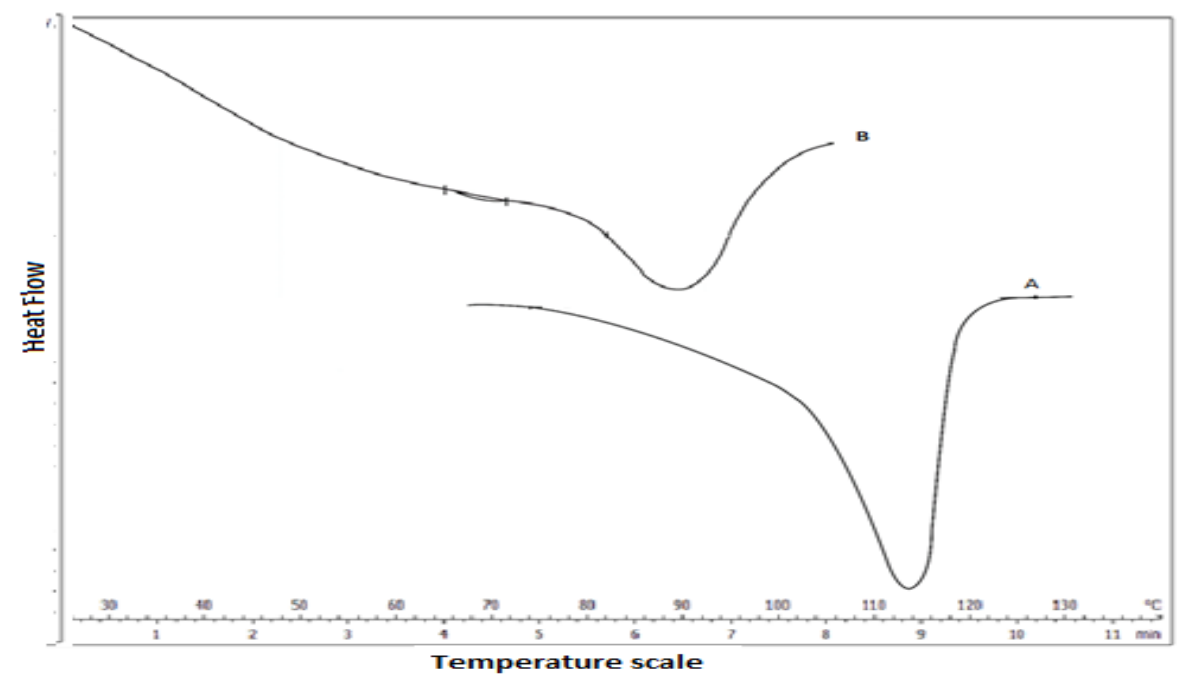

Figure 6. DSC thermograms of Pure azithromycin dihydrate A and optimized formulation B.

\section{MATERIALS AND METHODS}

\subsection{Materials}

Azithromycin dihydrate, Avicel PH 102, Aerosil 200, were obtained as gift samples from strides arcolab, India. Magnesium stearate and propylene glycol used were of analytical grade.

\subsection{Solubility studies}

Solubility studies of azithromycin dihydrate were carried out in propylene glycol, Tween 20, Span 20 and Polyethylene glycol 400 to select the best non-volatile solvent. The saturated solutions of drug in liquid vehicle were prepared by adding excess of drug to the liquid vehicle, kept on the orbital shaker for $48 \mathrm{~h}$ at $25^{\circ} \mathrm{C}$. The solutions were diluted, and their concentrations were analyzed by UV-spectrophotometer at $482 \mathrm{~nm}$ in phosphate buffer $\mathrm{pH} 6$ using $13.5 \mathrm{~mol} / \mathrm{L}$ sulfuric acid as color developer [9]. Three trials were made for determination of solubility in each solvent.

\subsection{Fourier transform infrared spectroscopy (FTIR) study}

Avicel PH102 and Aerosil 200 were selected as the carrier and coating material respectively. FTIR studies were performed using Bruker alpha $\mathrm{E}$ in a frequency range of 4000 to $400 \mathrm{~cm}^{-1}$. The physical mixture of drug, the carrier and coating materials were sprinkled on the ATR crystals. The IR beam was reflected from the internal surface of the crystal and produced an evanescent wave. This wave was projected orthogonally into the samples. The reflected radiation was returned to the detector and facilitated to generate the IR spectrum.

\subsection{Measuring liquid retention potential of carrier and coating material}

The liquid retention potential of both the carrier and coating material helps to determine the maximum quantity of liquid vehicle that can be retained by them without effecting their flowability and compressibility. Carrier or coating material weighing around $5 \mathrm{~g}$ was mixed with increasing quantity of propylene glycol in a mortar and pestle. The powder mixture was allowed to slide from a shiny metal plate at an optimum tilted position. The angle of slide was measured at an angle formed between the horizontal surface and the plate at which the powder admixture slides. From this the liquid retention potential $(\varphi)$ was calculated using the following formula (Eq. 2) [10, 11].

$$
\varphi=\frac{L}{Q}
$$

$\mathrm{L}=$ Weight of liquid

$\mathrm{Q}=$ Weight of carrier 


\subsection{Application of mathematical model for design of liquisolid compacts}

Spireas et al described the mathematical model of liquisolid compacts [12.13]. According to the theory the nonvolatile liquid retaining capacity of the carrier and coating material determines the acceptable flow ability and compressibility of the powder mixture. The theory is explained by certain terminologies like excipient ratio $(\mathrm{R})$, liquid loading factor (Lf) and liquid retention potential ( $\theta$ value) [10].The excipient ratio $(\mathrm{R})$ is termed as the ratio of weight of carrier $(\mathrm{Q})$ and coating material $(\mathrm{q})$.

$$
R=\frac{Q}{q}
$$

The liquid retention potential $(\varphi)$ is the ratio between weight of liquid $(\mathrm{L})$ and weight of carrier $(\mathrm{Q})$.

$$
\varphi=\frac{L}{Q}
$$

The liquid retention potential of carrier $\varphi_{c a}$ and coating $\varphi_{c o}$ is calculated to find out the required quantity of ingredients and the relationship between $\mathrm{R}$ and $\mathrm{Lf}$ is described by the following equation

$$
L f=\varphi c a+\varphi c o\left(\frac{1}{R}\right)
$$

\subsection{Employment of experimental design}

The design of liquisolid compact of azithromycin dihydrate is a multivariate procedure [11]. The amount of carrier and coating material can affect the flowability of the power mixtures and the release pattern. The effect of two factors like carrier and coating were evaluated for the flowability and release study of the liquisolid compact. A custom design with six experiments was constructed using software JMP version 8 . Using this design, the magnitude of effect of each variable on the resulting response on flowability and release was estimated. Each factor was tested at two levels low and high against the measured response as mentioned in table 7.

Table 7. Defining factor levels and Target product profile.

\begin{tabular}{lcc}
\hline & Factors & Levels \\
\hline Coating (mg) & Low level (-1) & High Level (+1) \\
Carrier (mg) & 6 & 24 \\
\hline Target product profile & 120 & 200 \\
\hline Angle of repose $(\boldsymbol{\theta})$ & Limits \\
Carr's Index $(\%)$ & $25-30$ \\
Hausner's Ratio & $3-10$ \\
$\%$ CDR at 45 mins & 1 \\
\hline
\end{tabular}

\subsection{Preparation of liquisolid compacts}

Azithromycin dihydrate was dissolved in propylene glycol sonicated for 10 mins. The appropriate amount of carrier and coating materials were mixed with the drug vehicle liquid system in a mortar and pestle. Mixtures of carrier and coating material were added at six different excipient ratios. Such six formulations were prepared as mentioned in table 8 . The powder mixture was evaluated for flowability, drug content and release studies [14, 15]. 
Table 8. Formulation table for azithromycin dihydrate in liquisolid compacts.

\begin{tabular}{cccccccc}
\hline \multirow{2}{*}{$\begin{array}{c}\text { Formulation } \\
\text { code }\end{array}$} & $\begin{array}{c}\text { Azithromycin } \\
\text { dihydrate in } \\
\text { propylene glycol } \\
\text { prow/w) }\end{array}$ & $\begin{array}{c}\text { Coating } \\
\mathbf{( m g )}\end{array}$ & $\begin{array}{c}\text { Carrier } \\
\mathbf{( m g )}\end{array}$ & $\begin{array}{c}\text { Excipient } \\
\text { Ratio (R) }\end{array}$ & $\begin{array}{c}\text { Loading } \\
\text { Factor (Lf) }\end{array}$ & $\begin{array}{c}\text { Magnesium } \\
\text { stearate } \\
\mathbf{( \% ) w / w ) ~}\end{array}$ \\
\hline F1 & 25 & 24 & 120 & 5 & 0.18 & 5 \\
F2 & 25 & 20 & 200 & 10 & 0.152 & 5 \\
F3 & 25 & 10 & 150 & 15 & 0.143 & 5 \\
F4 & 25 & 10 & 200 & 20 & 0.138 & 5 \\
F5 & 25 & 6 & 150 & 25 & 0.135 & 5 \\
F6 & 25 & 6 & 180 & 30 & 0.134 & 5 \\
\hline
\end{tabular}

\subsection{Evaluation of liquid solid compacts}

\subsubsection{Determination of flow properties}

Flow properties of the liquisolid compacts were determined by measurement of bulk density, tapped density, Carr's index, Hausner's ratio and angle of repose [13, 14].

\section{Bulk density}

It is the ratio of the mass and bulk volume of an untapped powder sample and was measured by bulk density apparatus, Servewell instruments Pvt. Ltd., India

\section{Tapped density}

The powders were tapped for 100 times in the bulk density apparatus, Servewell instruments Pvt. Ltd., India. Tapped density was calculated using the following formula (Eq. 6)

Tapped density= Mass/ Tapped Volume

\section{Compressibility index}

Compressibility index of the pulverized mixture was determined by Carr's index (Eq. 7) and Hausner's ratio (Eq. 8) and was calculated using the following formula

Carr's Index $=($ Tapped density - Bulk density $) * 100 /$ Tapped Density

Hausner's Ratio= Tapped density/Bulk density

\section{Angle of repose}

The powder mixture was allowed to flow from a fixed height funnel to make a pile of powder. The radius and height of the pile were measured. The angle of repose was calculated using the formula given below.

$$
\begin{aligned}
& \text { Angle of repose Tan } \theta=h / r \\
& h=\text { height of the pile } \\
& r=\text { radius of the pile }
\end{aligned}
$$

\subsubsection{Drug Content}

The liquisolid compact weighing 250mg of sample was dissolved in methanol in 100ml volumetric flask. From the stock solution, $1 \mathrm{ml}$ was taken and diluted to $100 \mathrm{ml}$ with phosphate buffer $\mathrm{pH} 6.0$ and the solution was analyzed spectrophotometrically at $482 \mathrm{~nm}$, using $13.5 \mathrm{~mol} / \mathrm{L}$ sulfuric acid as color developing agent [16].

\subsubsection{Dissolution studies}

The in vitro dissolution study was carried out in USP type II apparatus. Formulation equivalent to 250 mg was taken in the dissolution chamber containing a dissolution media of $900 \mathrm{ml}$ of phosphate buffer pH 6 . The temperature of the dissolution media was maintained at $37 \pm 0.5^{\circ} \mathrm{C}$. At a specified time interval samples 
were withdrawn and replaced with equal volume of fresh buffer solution. Three trials for each sample were performed. The samples were analyzed spectrophotometrically at $482 \mathrm{~nm}$ using $13.5 \mathrm{~mol} / \mathrm{L}$ sulfuric acid as color developer [17, 18].

\subsubsection{Comparative dissolution study}

The optimized formula equivalent to $250 \mathrm{mg}$ drug was taken for comparative dissolution study with pure drug. The dissolution carried for 45 mins in $900 \mathrm{ml}$ phosphate buffer $\mathrm{pH} 6$ in USP type II dissolution apparatus and assayed spectrophotometrically at $482 \mathrm{~nm}$ with $13.5 \mathrm{~mol} / \mathrm{L}$ sulfuric acid as color developer. Three trials were performed for the release study of the pure drug and the optimized formula.

\subsubsection{Differential scanning calorimetry study (DSC)}

The optimized formula of the liquid solid compact of azithromycin dihydrate was taken for DSC study to see the conversion of crystalline form of drug into its amorphous form. DSC analysis was performed using Perkin-Elmer pyris differential scanning calorimeter (DSC). The samples were heated at a constant rate $10^{\circ} \mathrm{C}$ $/ \mathrm{min}$ in a dry stream of nitrogen gas $(50 \mathrm{ml} / \mathrm{min})$ for all runs. Samples were heated from $0^{\circ} \mathrm{C}$ to $200^{\circ} \mathrm{C}$. The pure drug and the optimized formula were analyzed by the same manner.

Acknowledgements: The authors express their sincere gratitude to the Management, Principal of Krupanidhi college of pharmacy for their support to carry out the work. We thank Strides Arcolab for their generous support for the drug and chemicals.

Author contributions: Concept - S.B.; Design - S.B., I.P.,A.V; Supervision - S.B.; Resources - S.B., R.K, F.J.; Materials R.K, F.J.; Data Collection and/or Processing- S.B.,I.P., A.V., R.K., K.H.R.; Analysis and/or Interpretation - S.B.; Literature Search I.P., A.V., R.K., F.J., K.H.R; Writing - S.B.; Critical Reviews -S.B., I.P., A.V., R.K., F.J., K.H.R.

Conflict of interest statement: The authors declare no conflict of interest.

\section{REFERENCES}

[1] Pawar JD, Jagtap RS, Doijad RC, Pol SV, Desai JR, Jadhav VV, Jagtap SR. Liquisolid compacts: A promising approach for solubility enhancement. J Drug Deliv Ther. 2017; 7(4): 6-11. [CrossRef]

[2] Anand DS, Malavi RB, Vishal DG, Pooja MK. Liquisolid technique: a review. Int J Pharm Sci Res. 2017; 8(7): 27682775. [CrossRef]

[3] Jignesh S, Dhiren D, Ghanshyam P, Bhavin B, Upendra P, Darshan K. Liquisolid compacts: A novel approach to enhance the dissolution. Res J Pharm Tech. 2013; 6(3): 313-320.

[4] Patil DS, Magar D, Saudagar RB. Liquisolid technology: technique for formulation with enhanced bioavailability. World J Pharm Pharm Sci. 2013; 3(1): 368-387.

[5] Pusuluri DLS, Konkipudi VS, Brahmaih B, Pasam VR. Review on liquisolid compact technology. World J Pharm Res. 2015; 4(2): 293-306.

[6] Lode H, Borner K, Koeppe P, Schaberg T. Azithromycin- review of key chemical, pharmacokinetic and microbiological features. J Antimicrob Chemother. 1996; 37(1): 1-8.

[7] Idkaidek NM, Najib MN. Salem I, Jilani J. Physiologically Based IVIVC of Azithromycin. Am J Pharmacol Sci. 2014; 2(6): 100-102. [CrossRef]

[8] Govil S, Sadhna K, Sandeep A. Formulation and characterization of liquisolid compacts of valsartan. J Pham Res. 2012; 5(8): 4158-4162.

[9] Sultana S, Aryane MS, Hussain F, Fatima A. Degradation studies of azithromycin and its spectrophotometric determination in pharmaceutical dosage form. Pak J Pharm Sci. 2006; 19(2): 94-98.

[10] Chella N, Shastria N, Rama RT. Use of the liquisolid compact technique for improvement of the dissolution rate of valsartan. Acta Pharmaceutica Sinica B. 2012; 2(5): 502-508. [CrossRef]

[11] Poluri K, Suvarnala S, Puttugunta S, Govada KB, Pinnamraju DN. Formulation Development and evaluation of fast disintegrating tablets of Lamotrigine using liqui-solid technique. Int J Pharm Investig. 2012; 4(4): 207-214.

[12] Spireas S, Bolton M. Liquisolid systems and methods of preparing same. 1999, U.S. Patent 5,968,550.

[13] Spireas S. Liquisolid systems and methods of preparing same. 2002, U.S. Patent 6,423,339 B1. 
[14] Patel DS, Pipaliya RM, Surti N. Liquisolid Tablets for dissolution enhancement of a hypolipidemic drug. Indian J Pharm Sci. 2015; 77(3): 290-298.

[15] Soujanya B, Srujankumar M, Subhramanyam KV, Subhrajit M. Enhancement of solubility of efavirenz by liquisolid compact technique. Int J Innov Pharm Sci Res. 2013; 1(3): 347- 359.

[16] Lakshmi PK, Srinivas C, Kalpana B. Preparation and comparative evaluation of liquisolid compacts and solid dispersions of Valsartan. S J Pharm Sci. 2011; 4(2): 48-57.

[17] Zainab EJ. Formulation and evaluation of furosemide liquisolid compact. Int J App Pharm. 2017; 99(6): 39-48. [CrossRef]

[18] Shailesh TP, Hitesh HB, Dashrath MP, Suresh KD, Chhaganbhai NP. Formulation and evaluation of liquisolid compacts for olmesartan medoxomil. J Drug Del. 2013; Article ID 870579: 1-9. [CrossRef]

This is an open access article which is publicly available on our journal's website under Institutional Repository at http://dspace.marmara.edu.tr. 